\title{
Growth and characterization of BCN nanotubes with high boron and nitrogen content
}

\author{
GUO ZHANG, ZHIYE LIU, LIANPING ZHANG, LIQIANG JING and KEYING SHI* \\ Key Laboratory of Functional Inorganic Material Chemistry, Ministry of Education, Key Laboratory \\ of Material Chemistry, School of Chemistry and Chemical Engineering, Heilongjiang University, \\ Harbin 150080, People's Republic of China \\ e-mail: shikeying2008@yahoo.cn
}

MS received 12 August 2012; revised 4 January 2013; accepted 2 August 2013

\begin{abstract}
Multiwalled carbon nanotubes doped with boron and nitrogen (BCNTs) have been synthesized by chemical vapour deposition at temperatures ranging from $800^{\circ} \mathrm{C}$ to $950^{\circ} \mathrm{C}$. Their morphological and structural features have been studied by transmission electron microscope, which reveal that BCNTs have bamboo-like structure. The results of X-ray photoelectron spectroscopy demonstrated that the atomic ratio of $\mathrm{B}, \mathrm{C}$ and $\mathrm{N}$ of BCNTs is about $1: 4: 1$, when temperature is $850^{\circ} \mathrm{C}$. Electrooxidation performance of the BCNTs for NO at the modified electrodes was investigated. The results of cyclic voltammograms and the electrochemical impedance spectroscopy of BCNT-modified electrodes indicated that the activity of NO electrooxidation on $850^{\circ} \mathrm{C}$-modified electrodes is much stronger than others and the charge transfer resistance of NO electroxidation BCNT-modified electrode is the least. By this means, BCNT-modified electrodes showed excellent electrode materials for $\mathrm{NO}$ detection and other potential applications.
\end{abstract}

Keywords. Chemical vapour deposition (CVD); boron carbide nitride nanotubes (BCNTs); BCNT-modified electrode; NO electrooxidation.

\section{Introduction}

Carbon nanotubes (CNTs) have evoked considerable research interest owing to their remarkable electronic, mechanical, and optical properties. ${ }^{1,2}$ The unique properties of CNTs gave enormous impetus to researchers to explore analogous materials, such as boron nitride nanotubes (BNNTs), boron carbide nitride nanotubes (BCNTs). Thereinto, BNNTs are semiconductors characterized by wide band-gap energy of about $5.5 \mathrm{eV}$, independent of their radius and helicities. ${ }^{3}$ It is noteworthy that BCNTs are interesting in their own right and maybe able to offer different possibilities for technological applications that CNTs and BNNTs cannot provide. ${ }^{4}$ As ternary $\mathrm{B}-\mathrm{C}-\mathrm{N}$ materials, BCNTs are fascinating semiconductors with a 'tunable' band gap energy that is primarily controlled by the structure and chemical composition. ${ }^{5}$ It has also been found that BCNTs obtained by partial substituting of $\mathrm{C}$ for B or $\mathrm{N}$ would alter the hardness and electronic properties. ${ }^{6}$

*For correspondence
Compared to carbon nanotubes, BCNTs have some advantageous properties such as semiconductive, ${ }^{7}$ mechanical, ${ }^{8}$ being having good electrical performance and higher resistance to oxygen. ${ }^{9}$ All these properties provide BCNTs great potential for application in electronics, ${ }^{10}$ optoelectronics, ${ }^{11}$ high temperature lubricants ${ }^{12}$ and other applications. ${ }^{13}$ Especially in nano-electrochemistry, it provides the possibility to produce materials with tunable electronic properties. Therefore, as one of the important $\mathrm{B}-\mathrm{C}-\mathrm{N}$ materials, BCNTs have been intensively studied theoretically and experimentally. ${ }^{14-16}$ BCNNTs are particularly useful in nanodevice applications where high-strength and semiconductor properties are desired. In terms of their structural stability, theoretical calculations predict that segregation of the $\mathrm{BN}, \mathrm{C}$, and $\mathrm{BCN}$ domains tends to occur; the most stable structure seems to optimize the chemical bond energy by maximizing the number of $\mathrm{C}-\mathrm{C}$ and $\mathrm{B}-\mathrm{N}$ bonds. Their structure and composition appear to be sensitive to the growth method and actual growth parameters. Therefore, systematic studies of the characteristics of BCNTs grown using specific techniques are of great importance both to further their utilization and to develop suitable fabricationk methods. 
In recent years, several synthesis techniques have been developed for growth of BCNTs, including arc discharge, ${ }^{16}$ laser ablation, ${ }^{17}$ pyrolysis ${ }^{18}$ and chemical vapour deposition (CVD). ${ }^{19}$ However, most of these synthesis methods were carried out at high temperatures. ${ }^{20}$ Kim et al. ${ }^{16}$ synthesized BCNTs using BN power, iron phthalocyanine and $\mathrm{NH}_{3}$ as $\mathrm{B}, \mathrm{C}, \mathrm{N}$ source at $1200^{\circ} \mathrm{C}$. Wu et al. ${ }^{22}$ synthesized $\mathrm{BCN}$ nanotubes with CVD derived using carbon NTs together with $\mathrm{B}_{2} \mathrm{O}_{3}$ and $\mathrm{N}_{2}$ at $1600^{\circ} \mathrm{C}$ for half an hour. It was found that the new trend of low temperature synthesis was necessary. Thus, to develop a low-temperature, high-quality synthesis method for BCNTs with a higher production yield is the highest priority for their practical application.

At present, NO is an active molecule with short half-life, low concentration, low stability, high reactivity and other very active free radicals present in the environment. ${ }^{23}$ Electrocatalytic properties for NO electrooxidation have also been investigated based on the modified electrodes with carbon nanotubes and analogous carbon nanotube structure. ${ }^{24}$ We expect to establish a highly sensitive method to detect $\mathrm{NO}$ in aqueous solution with BCNTs. Thus, preparing BCNTs and investigating their $\mathrm{NO}$ electrooxidation property are very meaningful.

In the present study, we report on the direct, largescale synthesis of ternary BCNNTs, which carried out a simple growth method by using ethylenediamine $\left(\mathrm{H}_{2} \mathrm{NCH}_{2} \mathrm{CH}_{2} \mathrm{NH}_{2}\right)$ solution of borohydride $\left(\mathrm{NaBH}_{4}\right)$ and dicyclopentadienyl iron as source material. Through the change of reaction temperature, four different types of multiwalled BCNNTs (different atomic ratios of $\mathrm{B}: \mathrm{C}: \mathrm{N})$ are prepared. All the processes have been simple and low cost. This approach makes it possible to control the morphology, and the chemical composition of BCNNTs could be tailored by varying reaction temperature. Moreover, the electrocatalytic properties for NO electrooxidation have also been investigated by cyclic voltammetry (CV) and electrochemical impedance spectroscopy (EIS).

\section{Experimental}

\subsection{Material preparation}

BCNTs were synthesized via CVD, which was carried out in a horizontal reactor consisting of a quartz tube. $\mathrm{NaBH}_{4}$ was used as boron precursor, $\mathrm{Fe}\left[\mathrm{C}_{5} \mathrm{H}_{5}\right]_{2}$ and $\mathrm{H}_{2} \mathrm{NCH}_{2} \mathrm{CH}_{2} \mathrm{NH}_{2}$ were chosen as carbon and nitrogen sources. We used froth iron powder as a catalyst precursor and placed it in a quartz boat in a system, which is composed of an electrical furnace internally equipped with a quartz tube. One end of the quartz tube is connected to a wide-mouth bottle filled with the source solution. First, nitrogen gas was introduced into the sample quartz tube to remove oxygen adsorbed on the surface. Then, $\mathrm{H}_{2}$ was introduced into the system to reduce the catalyst at reaction temperature for $30 \mathrm{~min}$. Subsequently, B, C, N sources were introduced into the reactor with $\mathrm{N}_{2}$ as carrier gas, and the reaction was maintained at different reaction temperatures $\left(800^{\circ} \mathrm{C}-950^{\circ} \mathrm{C}\right)$ for $1 \mathrm{~h}$. After cooling down to room temperature in a flow of $\mathrm{N}_{2}$, the products were collected.

\subsection{Electrochemical experiments}

Glassy carbon (GC) electrode with diameter of $4 \mathrm{~mm}$ was polished before each experiment, then sonicated in ethanol, acetone and water, respectively and dried at ambient temperature. The BCNNTs synthesized at different temperature were used to modify the GC electrode. Each BCNNTs of quantity $0.25 \mathrm{mg}$ was dispersed in $10 \mathrm{~mL}$ acetone accompanied by ultrasonic process to get a suspension. Suspension of $10 \mu \mathrm{L}$ was dropped on the surface of the GC electrode, and the solvent was gradually evaporated under an IR lamp. Then three kinds of modified electrodes were obtained. Electrochemical experiments were performed in an electrolytic cell with three electrodes. The GC electrode or various SWCNT-modified electrodes were used as a working electrode, a platinum sheet served as an auxiliary electrode, and an $\mathrm{Ag} / \mathrm{AgCl}$ electrode was used as a reference electrode. $\mathrm{KH}_{2} \mathrm{PO}_{4}-\mathrm{NaOH}$ buffer solution (PBS) of $0.1 \mathrm{~mol} \mathrm{~L}^{-1}$ was taken as a blank solution, the $\mathrm{pH}$ value was 6.8 . The solution was bubbled by high purity $\mathrm{N}_{2}$ (99.999\%), for $30 \mathrm{~min}$ to remove oxygen, and then the solution was bubbled with pure NO (99.999\%) for 30 min to prepare a NO-saturated solution. The CV was measured by LK98IIB electrochemical analyser (Lanlik Instrument Co. Ltd., Tianjin, China), the scanning speed was $50 \mathrm{mV} \mathrm{s}^{-1}$, and the range of potential sweep was $300-1400 \mathrm{mV}$. The EIS was measured by IM6e impedance measurement unit (ZAHNER Elektrik, Germany). The AC voltage amplitude was $10 \mathrm{mV}$, the frequency range was from $10 \mathrm{mHz}$ to $100 \mathrm{kHz}$, and the data were processed with Zview2 software.

\subsection{Material characterization}

The morphology and structure of the products were studied using transmission electron microscopy (TEM, JEM-2100). C, N and B elements were quantified by 
X-ray photoelectron spectroscopy (XPS, VG ESCALAB 250) excited by an X-ray source of $\mathrm{Mg} \mathrm{K \alpha}$ $(\mathrm{hm}<1253.6 \mathrm{eV})$ in an ultrahigh vacuum chamber with a base pressure of $<2 \times 10^{-8}$ Torr. The Fourier transform infrared (FT-IR) spectra were carried out with FTIR Spectrometer (Perkin Elmer Spectrum). Cyclic voltammetry $(\mathrm{CV})$ measurements were performed by BAS100B electrochemical analyser (Germany). The experiments were carried out at $0.05 \mathrm{~V} \mathrm{~s}^{-1}$. A conventional three-electrode configuration was used with a GC modified electrode as working electrode, an $\mathrm{Ag} / \mathrm{AgCl}$ electrode (in $\mathrm{KCl}$ saturated solution) as reference electrode, and a platinum sheet as counter electrode. The prepared BCNTs were dropped onto a modified glass carbon to measure their NO electro-oxidation performance.

\section{Results and discussion}

Figure 1 presents TEM images of BCNTs synthesized by CVD method at temperatures ranging from $\left(800^{\circ} \mathrm{C}-950^{\circ} \mathrm{C}\right)$. Figure $1(\mathrm{a}-\mathrm{c})$ shows the low and high magnification TEM images of BCNTs synthesized at $800^{\circ} \mathrm{C}$. Figure $1(\mathrm{a}, \mathrm{b})$ reveal that BCNTs possess curved intersecting inner wall. In fact, figure 1(c) illustrates a tubular structure with opened edges, and the diameter of BCNTs is about $30-50 \mathrm{~nm}$. It is notable that these nanofibres have been produced only at $800^{\circ} \mathrm{C}$. Figure $1(d-f)$ are the TEM images of BCNTs synthesized at $850^{\circ} \mathrm{C}$. It can be observed that the BCNTs are composed of many curved graphite layers (figure 1e, f). It is the curved graphite layers that make up the stacked 'bamboo-like' compartments. The diameter

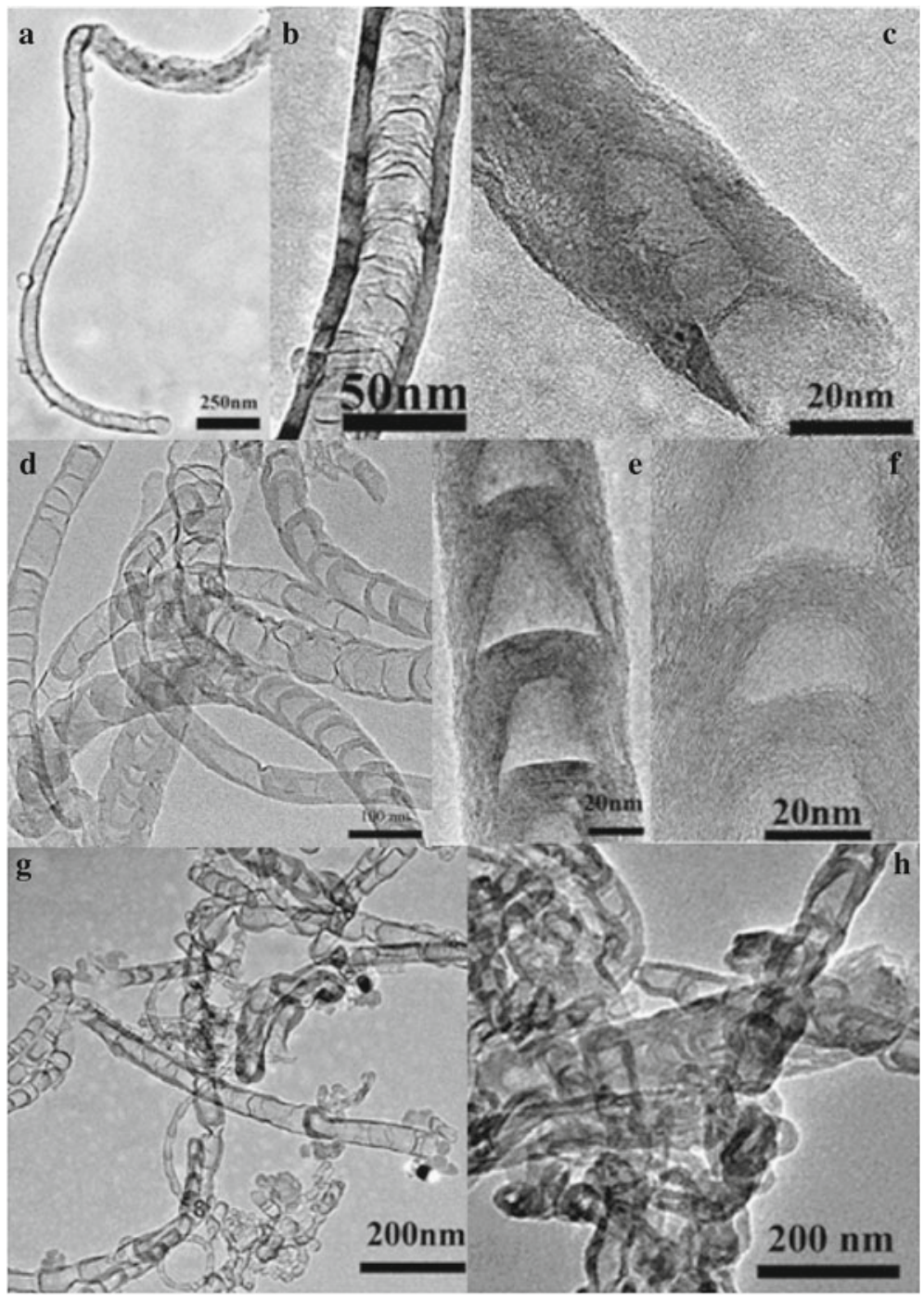

Figure 1. TEM images of BCNTs obtained by different synthesis temperatures: (a), (b), (c) $800^{\circ} \mathrm{C} ;$ (d), (e), (f) $850^{\circ} \mathrm{C} ;(\mathbf{g}) 900^{\circ} \mathrm{C}$; (h) $950^{\circ} \mathrm{C}$. 
of BCNT is about $60 \mathrm{~nm}$. High-resolution transmission electron microscopy (HRTEM) image clearly shows that the BCNT are multiwalled and have bamboo-like structure with a very frequent and regular compartmentalized morphology which is a typical result of doped heteroatoms. Figure 1(g) shows that the distorted structural BCNTs synthesized at $900^{\circ} \mathrm{C}$ result in bending and curling, the bamboo-like structure is irregular. Figure 1(h) shows that BCNTs synthesized at $950^{\circ} \mathrm{C}$ are of pell-mell structure, the compartment layers are curved to connect with the distorted wall. The above result suggests that BCNT growth and atom rearrangement occur at the crush edges due to their high temperature. In addition, it should be noted that the growth of the BCNTs progresses outwards with an increase in the diameter as further layers are added during the formation. ${ }^{25}$ Results demonstrate that temperature had a great effect on the morphology of the BCNTs, and the best synthesized temperature of BCNTs is $850^{\circ} \mathrm{C}$.

Figure 2 shows typical infrared absorption spectra of the sample groups of BCNTs grown at various temperatures. Figure 2(a-d) shows two bands around $1386 \mathrm{~cm}^{-1}$ and $795 \mathrm{~cm}^{-1}$, corresponding to in-plane B-N transverse optical mode ${ }^{26}$ and out-of-plane $\mathrm{B}-\mathrm{N}-\mathrm{B}$ bending mode of BCNTs. ${ }^{27} \mathrm{~A}$ very wide absorption band at around $1020-1220 \mathrm{~cm}^{-1}$ is observed. ${ }^{28}$ The absorption bands at $1045 \mathrm{~cm}^{-1}$ and $1125 \mathrm{~cm}^{-1}$ were due to $\mathrm{C}-\mathrm{N}$ and $\mathrm{C}-\mathrm{B}^{29}$ bending vibration, respectively. The absorption band at $1631 \mathrm{~cm}^{-1}$ is assigned to the presence of $\mathrm{sp}^{2}$-bonded $\mathrm{C}=\mathrm{N}$ bond. ${ }^{30,31} \mathrm{In}$ addition, the absorption band centred at $3445 \mathrm{~cm}^{-1}$ is related to $\mathrm{N}-\mathrm{H}$ or $\mathrm{O}-\mathrm{H}$ stretching vibrations or water molecules. ${ }^{32}$ The FT-IR spectra confirm that the $\mathrm{B}$ and $\mathrm{N}$ atoms have been doped into the BCNTs.

The chemical states of $\mathrm{B}, \mathrm{C}$, and $\mathrm{N}$ elements were investigated using X-ray photoelectron spectroscopy

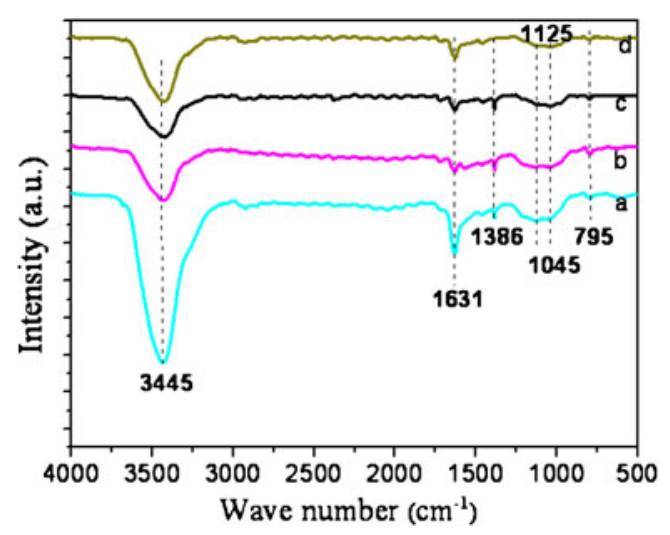

Figure 2. FT-IR spectra of BCNTs prepared at different temperatures: (a) $800^{\circ} \mathrm{C}$, (b) $850^{\circ} \mathrm{C}$, (c) $900^{\circ} \mathrm{C}$ and (d) $950^{\circ} \mathrm{C}$.
(XPS) spectra. The chemical composition of the asprepared BCNTs is exhibited in table 1. According to the results of the XPS, BCNTs have the highest doped $\mathrm{B}$ and $\mathrm{N}$ at $850^{\circ} \mathrm{C}$. The chemical states of $\mathrm{B}, \mathrm{C}$, and $\mathrm{N}$ elements of the sample under $850^{\circ} \mathrm{C}$ are further researched. Since it is important for the $\mathrm{N}$ element in different samples to adsorb NO, the four samples of chemical states of $\mathrm{N}$ have been investigated. It is noted that the atomic ratio of $\mathrm{B}, \mathrm{C}$ and $\mathrm{N}$ of $\mathrm{BCNT}$ s synthesized by $850^{\circ} \mathrm{C}$ is close to $1: 4: 1$. To further investigate the local structure of the as-obtained materials, the $1 \mathrm{~s}$ peaks of $\mathrm{N}$, $\mathrm{C}, \mathrm{B}$ and $\mathrm{O}$ are revealed, respectively, in figure 3(a), and these peaks are separated by Gaussian fitting. As shown in figure 3(b), the spectrum is mainly composed of two peaks through Gaussian fitting. The peak of N1s with binding energies of $398.2 \mathrm{eV}$ can be assigned to the $\mathrm{N}$ atoms in pyridine-like $\mathrm{N}-\mathrm{C}$ structures; ${ }^{33-35}$ the peak of N1s with binding energies of $399.0 \mathrm{eV}$ can be assigned to the $\mathrm{N}$ atoms bonded to $\mathrm{C}$ atoms as graphite-like structures. ${ }^{11,35}$ The sp2-bonded $\mathrm{B}=\mathrm{N}$ and $\mathrm{C}=\mathrm{N}$ bonds are known to emit photoelectrons that bonded to the core state of $\mathrm{N}$ at $398.0-398.3 \mathrm{eV}$ and $399-400 \mathrm{eV}$, respectively. ${ }^{33-35}$ The content of pyridine-like $\mathrm{N}$ in the sample at $850^{\circ} \mathrm{C}$ is highest among the four samples. Similarly, the $\mathrm{C} 1 \mathrm{~s}$ spectrum in figure 3(c) has three peaks with a broad shoulder. The curve-fitted $\mathrm{C} 1 \mathrm{~s}$ spectrum shows three main peaks centred at 284.5, 285.2 and 286, which are ascribed to $\operatorname{sp} 2 \mathrm{C}=\mathrm{B}, \mathrm{C}=\mathrm{C}$ and $\mathrm{C}=\mathrm{N}$, respectively. ${ }^{36-38}$ The presence of negligible $\mathrm{C}=\mathrm{O}$ bonding structures located at $289.4 \mathrm{eV}$ are due to surface contaminant oxidized dangling bonds at the defect sites of tube walls. The B 1s spectrum in figure 3(d) indicates that there are two bonding states. The peak at $190.5 \mathrm{eV}$ corresponds to boron bonded to carbon (B-C bond), the peak at $191.2 \mathrm{eV}$ is assigned to boron bonded to nitrogen $(\mathrm{B}=\mathrm{N}$ bond $) .{ }^{16}$ This spectrum indicates that most $\mathrm{B}$ are bonded to $\mathrm{N}$ in the form of $\mathrm{sp} 2$ bonded $\mathrm{B}=\mathrm{N}$ bonds, the results suggest that the boron and nitrogen bonding exists in the structure of as-grown nanotubes.

Figure 4 represents the schematic procedure of the preparation of BCNNTs composites under different growth steps. It is clear that catalyst particle BCNNTs were catalytically synthesized with $\mathrm{C}$ and $\mathrm{N}$ resources

Table 1. Total elements concentration (at.\%) of BCNTs at different temperature.

\begin{tabular}{lcrrr}
\hline Sample & O1s $\%$ & N1s $\%$ & C1s \% & B1s \% \\
\hline $800^{\circ} \mathrm{C}$ & 6.46 & 9.77 & 77.35 & 6.43 \\
$850^{\circ} \mathrm{C}$ & 8.05 & 14.88 & 62.01 & 15.07 \\
$900^{\circ} \mathrm{C}$ & 5.46 & 13.03 & 69.74 & 11.77 \\
$950^{\circ} \mathrm{C}$ & 6.11 & 7.76 & 79.21 & 6.91 \\
\hline
\end{tabular}



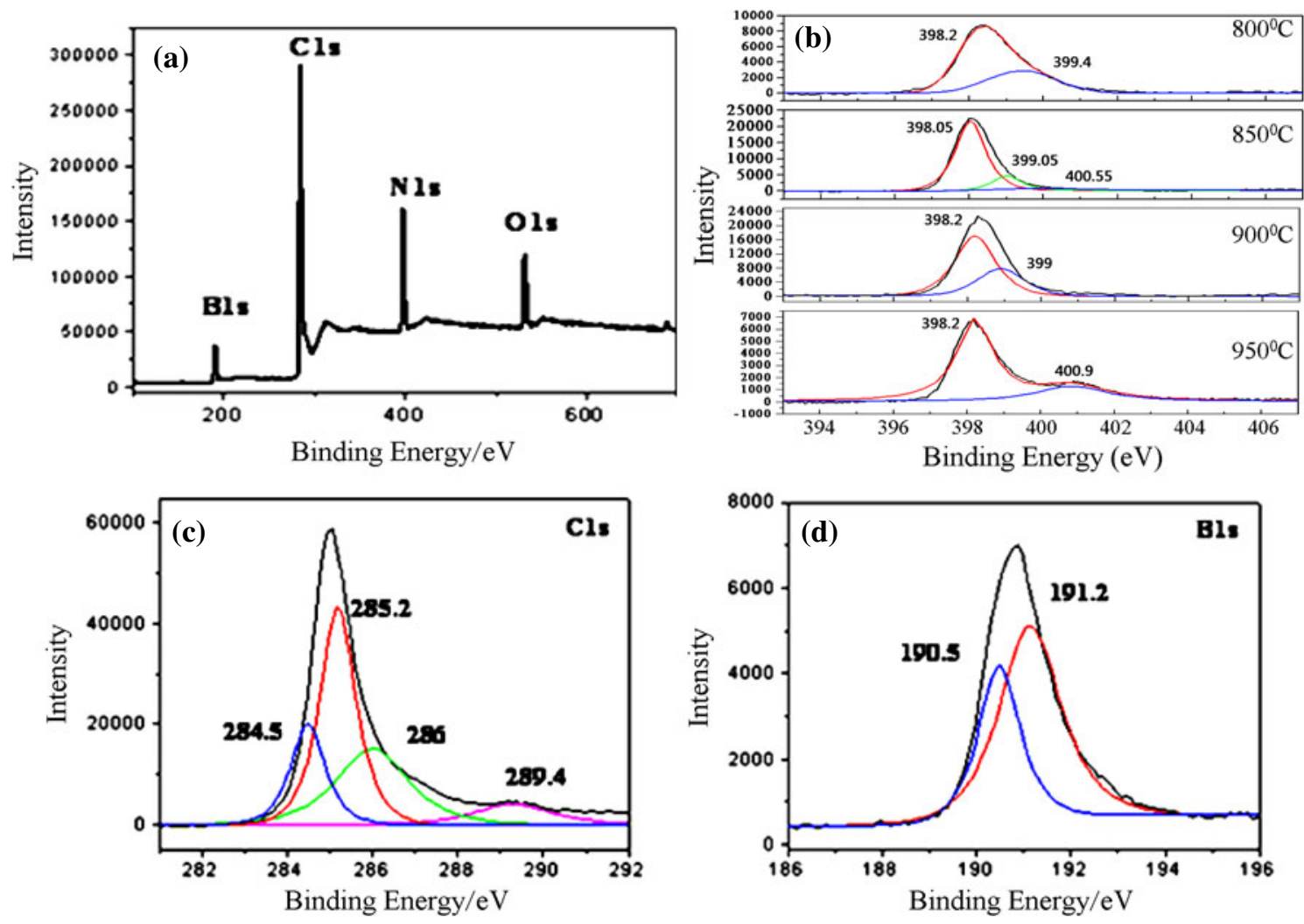

Figure 3. XPS spectrum of BCNTs synthesized at $850^{\circ} \mathrm{C}$ : (a) 1s peaks of $\mathrm{N}, \mathrm{C}, \mathrm{B}$, and $\mathrm{O}$; (b) $\mathrm{N}$ 1s; (c) C $1 \mathrm{~s}$ and (d) B1s peaks separated by Gaussian fitting.

over $\mathrm{Fe}-\mathrm{Mg}$ catalyst and the reaction temperature was optimized for the first step. At reaction temperature, carbon atoms that also originate from the pyrolysis of $\mathrm{C}$ and $\mathrm{N}$ resources start reacting on the hot metal catalyst clusters, and thus the $\mathrm{N}$-doped carbon multiwall part is first synthesized, $\mathrm{N}$ can be doped as pyridinelike $\mathrm{N}$ structures or as graphite-like $\mathrm{N}$ structures. The $\mathrm{C}$ atoms found around $\mathrm{N}$ atoms as graphite-like structures are active because $\mathrm{N}$ atoms are modified. In the second stage of synthesis, the chemical vapour deposition (CVD) process gives rise to a B-doped carbon layer on the already-deposited $\mathrm{N}$-doped carbon multiwall.
The $\mathrm{B}$ atoms replace the $\mathrm{C}$ atoms around the $\mathrm{N}$ atoms as graphite-like structures or occupy the centre of the pyridine-like N, leading to the formation of BCNNTs.

Figure 5 shows the result of $\mathrm{CVs}$ at various temperatures BCNT-modified electrodes in $0.1 \mathrm{M}$ phosphate buffer solution (PBS, pH 6.8) saturated with NO. $\mathrm{CV}$ studies were performed within the potential range of 0.3 to $1.4 \mathrm{~V}$. The values of peak current density and peak potential of BCNTs synthesized at $800^{\circ} \mathrm{C}$, $850^{\circ} \mathrm{C}, 900^{\circ} \mathrm{C}, 950^{\circ} \mathrm{C}$ at modified electrodes are shown in table 2. The peak current reflects the rate of the electrode reaction, and the peak potential reflects the

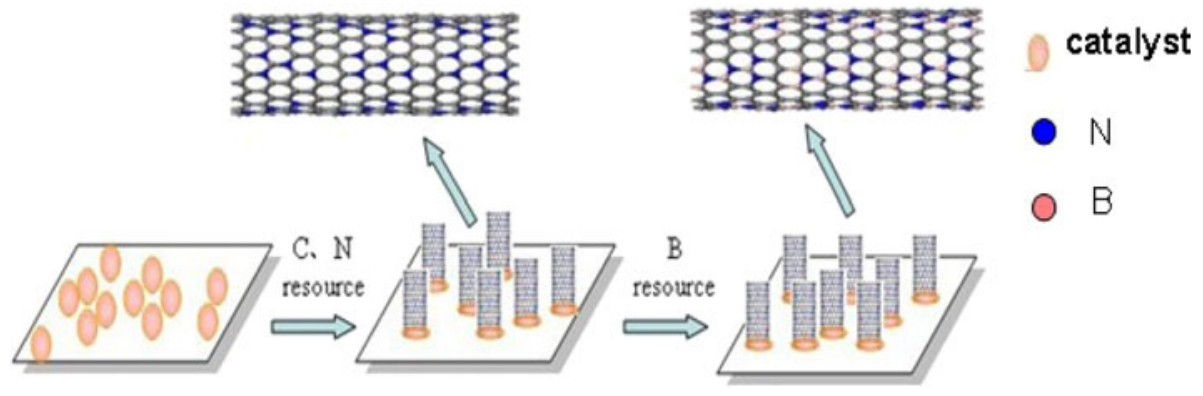

Figure 4. Schematic diagram of the fabrication of BCNNTs. 


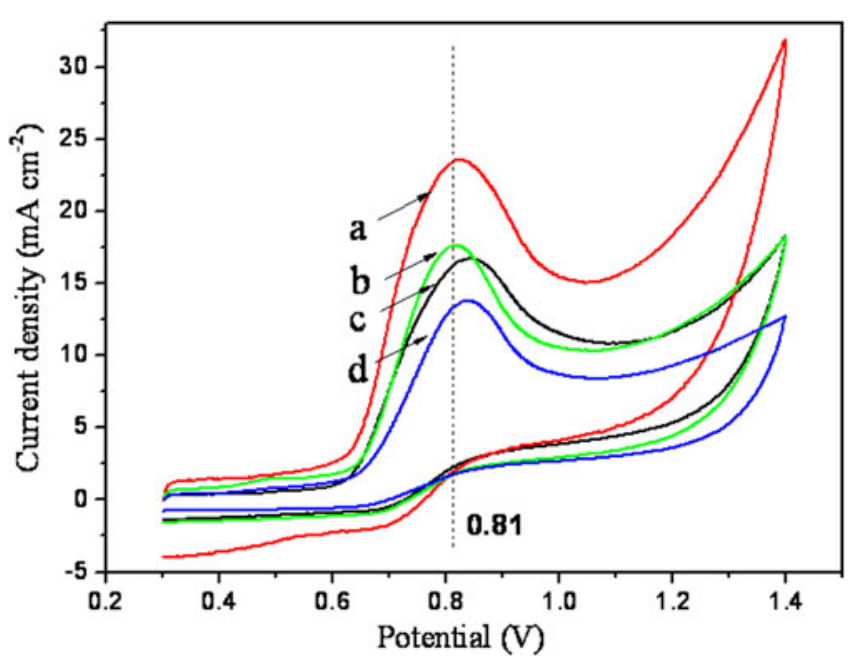

Figure 5. Cyclic voltammograms at (a) $850^{\circ} \mathrm{C}$, (b) $900^{\circ} \mathrm{C}$, (c) $800^{\circ} \mathrm{C}$ and (d) $950^{\circ} \mathrm{C}$ BCNT-modified electrodes in PBS saturated with $\mathrm{NO}$ (scan rate of $50 \mathrm{mV} / \mathrm{s}$ ).

activation energy of the electrode reaction. In general, the higher the peak current density, the faster the reaction rate of NO electrooxidation. ${ }^{39}$ It can be seen that BCNT-modified electrode synthesized at $850^{\circ} \mathrm{C}$ has the highest current density and the one with most negative peak potentials. The anodic peak potential is $0.822 \mathrm{~V}$ and the peak current density is $23.53 \mathrm{~mA} / \mathrm{cm}^{2}$. Meanwhile, the order of $\mathrm{NO}$ electrooxidation rate of various BCNT-modified electrodes is BCNT- $850^{\circ} \mathrm{C}>\mathrm{BCNT}$ $900^{\circ} \mathrm{C}>\mathrm{BCNT}-800^{\circ} \mathrm{C}>\mathrm{BCNT}-950^{\circ} \mathrm{C}$. Thus, the rate of NO electrooxidation of BCNT- $850^{\circ} \mathrm{C}$ modified electrode is the highest among all the BCNT-modified electrodes. This result is attributed to increased boronnitrogen doping of BCNT leading to increased defects and improved activity on BCNT surface. Figure 3(b) and table 1 reveal the XPS N 1 s spectra and N content of the samples, the order of concentration of $\mathrm{N}$ atom in nanotubes is $\mathrm{BCNT}-850^{\circ} \mathrm{C}>\mathrm{BCNT}-900^{\circ} \mathrm{C}>$ BCNT $-800^{\circ} \mathrm{C}>\mathrm{BCNT}-950^{\circ} \mathrm{C}$ among the four BCNTs.

Table 2. The values of peak potential, current density and charge transfer resistance (Rct) for NO electrooxidation.

\begin{tabular}{lccc}
\hline & \multicolumn{2}{c}{ NO electrooxidation peak } & \\
\cline { 2 - 3 } $\begin{array}{l}\text { Modified } \\
\text { electrode }\end{array}$ & Potential $(\mathrm{V})$ & $\begin{array}{c}\text { Current density } \\
\left(\mathrm{mA} / \mathrm{cm}^{2}\right)\end{array}$ & $\operatorname{Rct}(\Omega)$ \\
\hline $800^{\circ} \mathrm{C}$ & 0.839 & 16.71 & 381 \\
$850^{\circ} \mathrm{C}$ & 0.822 & 23.53 & 315 \\
$900^{\circ} \mathrm{C}$ & 0.815 & 17.61 & 352 \\
$950^{\circ} \mathrm{C}$ & 0.838 & 13.76 & 418 \\
\hline
\end{tabular}

It can be speculated that $\mathrm{N}$ content in BCNTs is important for electrocatalysis capability. Therefore, electrocatalysis capability increases with nitrogen content in BCNTs synthesized under different temperatures. The XPS N 1 s spectra are mainly composed of two peaks through Gaussian fitting (figure 3b). The 398.2 eV peak can be assigned to $\mathrm{N}$ atoms in the pyridine-like $\mathrm{N}-\mathrm{C}$ structures, the $399 \mathrm{eV}$ peak can be assigned to the $\mathrm{N}$ atoms bonded to $\mathrm{C}$ atoms as graphite-like structures. Either pyridine-like $\mathrm{N}$ or graphite-like $\mathrm{N}$ is important to adsorb NO and favour NO catalytic oxidation. ${ }^{40}$ Therefore, the increase of N element in BCNTS is benefit for the NO catalytic oxidation. In addition, in four samples, the BCNTs are uniform and the atomic ratio of $\mathrm{B}, \mathrm{C}$ and $\mathrm{N}$ of BCNTs synthesized at $850^{\circ} \mathrm{C}$ is close to $1: 4: 1$. The concentration of $\mathrm{B}$ and $\mathrm{N}$ atoms in nanotubes is highest among the four BCNTs. In addition, it can be seen in figure 3(b) that the sample which was prepared at $850^{\circ} \mathrm{C}$ contains a large amount of the pyridine-like $\mathrm{N}$. Pyridine-like $\mathrm{N}$ is very important because of the extra lone pair of electrons on the $\mathrm{N}$ atom, which increases electron density on graphitic edge planes. Therefore, it is reasonable to expect that edge planes, which are commonly known to be reactive sites for the oxidation of NO, will show increased reactivity due to electron density garnered from the incorporation of $\mathrm{N}$ in pyridinelike coordination. ${ }^{40,41}$ Therefore, BCNT- $850^{\circ} \mathrm{C}$ reflects higher electrocatalytic activity.

Electrochemical impedance spectroscopy (EIS) is a powerful tool which can provide a wealth of information for electrode reactions. We employed EIS to further investigate the activity of these two electrodes towards PBS saturated with NO solution electrooxidation. For comparison, figure 6 presents the Nyquist plots of BCNT-modified electrodes measured in PBS saturated with NO solution at a potential of $0.60 \mathrm{~V}$. An AC voltage amplitude of $0.01 \mathrm{~V}$ was used in the frequency range of $1 \mathrm{~Hz}$ to $100 \mathrm{kHz}$. Resistance can be obtained from the analysis of EIS spectra by using Z-view software. Diameter of the capacitive semicircle which represents the resistance of charge transfer decreases when the electrode potential is $0.6 \mathrm{~V}$. As shown in figure 6 and table 2, there are big capacitive semicircles of BCNTs synthesized at $950^{\circ} \mathrm{C}$ and BCNT-modified electrodes synthesized at $850^{\circ} \mathrm{C}$ are small. The change in capacitive semicircles occurs due to the influence of the products charge transfer resistance. The value of charge transfer resistance (Rct) of BCNT-modified electrodes synthesized at $800^{\circ} \mathrm{C}, 850^{\circ} \mathrm{C}, 900^{\circ} \mathrm{C}$ and $950^{\circ} \mathrm{C}$ are shown in table 2. It is known that the lower Rct of the modified electrode corresponds to the faster rate of charge transfer. The order of charge transfer rate is $\mathrm{BCNT}-850^{\circ} \mathrm{C}>\mathrm{BCNT}-900^{\circ} \mathrm{C}>\mathrm{BCNT}-800^{\circ} \mathrm{C}>$ 


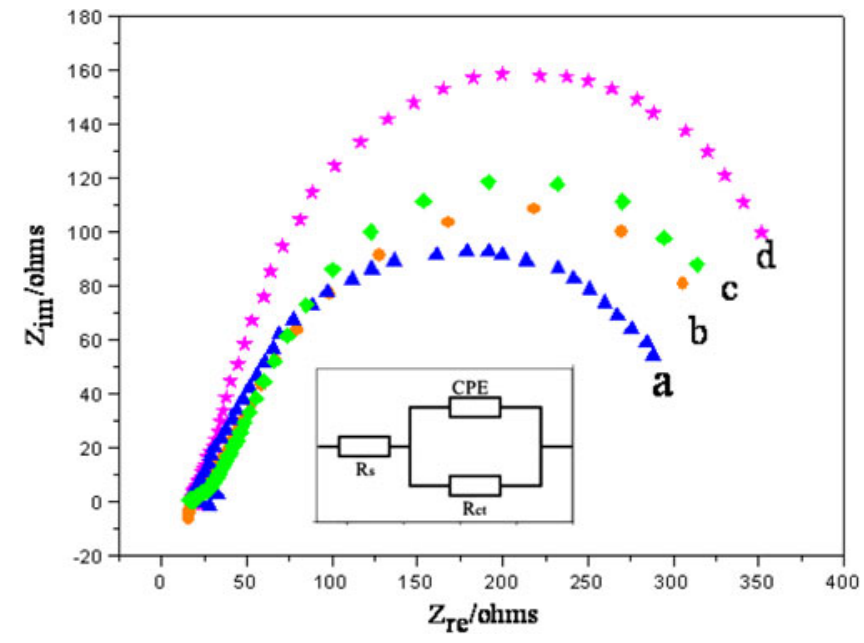

Figure 6. Nyquist plot of electrochemical impedance spectroscopy of (a) $850^{\circ} \mathrm{C}$, (b) $900^{\circ} \mathrm{C}$, (c) $800^{\circ} \mathrm{C}$ and (d) $950^{\circ} \mathrm{C}$ BCNTs.

BCNT- $950^{\circ} \mathrm{C}$. It shows that the diameter of capacitive semicircle increases with increase in electrode potential.

\section{Conclusion}

Our study discusses the structure and properties of carbon doped with nitrogen and boron via CVD procedure in the temperature ranges $800^{\circ} \mathrm{C}-950^{\circ} \mathrm{C}$. TEM indicates that the BCNTs at $850^{\circ} \mathrm{C}$ usually have a perfect bamboo-like structure. XPS data of $\mathrm{BCNT}-850^{\circ} \mathrm{C}$ reveal that the $\mathrm{B}, \mathrm{C}$ and $\mathrm{N}$ atomic ratio is nearly $1: 4: 1$. This reveals significant binding states of $\mathrm{B}=\mathrm{N}$ and $\mathrm{C}=\mathrm{N}$. Electrocatalytic properties of BCNTs have been investigated by $\mathrm{CV}$ in $0.1 \mathrm{M}$ PBS at room temperature. Corresponding results show that $\mathrm{BCNT}-850^{\circ} \mathrm{C}$ can be taken as an optimal electrode material. The sensitivity of BCNT- $850^{\circ} \mathrm{C}$-modified electrode is the highest of all experimental electrodes. The Rct of $\mathrm{NO}$ electroxidation BCNT- $850^{\circ} \mathrm{C}$-modified electrode is the least. Therefore, $\mathrm{BCNT}-850^{\circ} \mathrm{C}$ can be taken as an optimal electrode material. The sensitivity of $\mathrm{BCNT}-850^{\circ} \mathrm{C}$-modified electrode is the highest of all experimental electrodes. This suggests that BCNT-based electrodes have potential electronic applications.

\section{Acknowledgement}

This work was supported by the Union Funds of Scientific Research Fund of Heilongjiang Provincial Education Department (No. 12521421).

\section{References}

1. Dominik E 2010 Chem. Rev. 1101348

2. Abhishek K K, Erkan K and Brian W S 2009 J. Mater. Sci. 446020

3. Renzhi M, Yoshio B and Tadao S 2002 Adv. Mater. 145

4. Yu J and Bai X D 2000 Chem. Phys. Lett. 323529

5. Su C Y, Juang Z Y and Chen K F 2009 J. Phys. Chem. C113 14681

6. Pattanayak J, Kar T and Scheiner S 2002 J. Phys. Chem. A106 2970

7. Lei W W, Portehault D and Dimova R $2011 \mathrm{~J}$. Am. Chem. Soc. 1337121

8. Golberg D, Costa P and Lourie O 2007 Nano Lett. 7 2146

9. Yin L W, Bando Y and Golberg D 2005 J. Am. Chem. Soc. 12716354

10. Yang X X, Liu L and Wu M H 2011 J. Am. Chem. Soc. 13313216

11. Terrones M, Grobert N and Terrones H 2002 Carbon 40 1665

12. Raidongia K, Jagadeesan D and Mousumi U K 2008 J. Mater. Chem. 1883

13. Wang W L, Bai X D, Liu K H and Xu Z 2006 J. Am. Chem. Soc. 1286530

14. Bhattacharya S, Majumder C and Das G P 2009 J. Phys. Chem. C113 15783

15. Matos M A, Azevedoa S and Kaschny J R 2009 Solid State Commun. 149222

16. Kim S Y, Park J and Choi H C 2007 J. Am. Chem. Soc. 1291705

17. Terrones M, Golberg D, Grobert N, Seeger T, ReyesReyes M, Mayne R, Kamalakaran R, Dorozhkin P, Dong Z C, Terrones H, Ruhle M and Bando Y 2003 Adv. Mater. 151899

18. Dominick V, Lanzisera and Andrews L 1997 J. Phys. Chem. A101 7134

19. Sen R, Satishkumar B C, Govindaraj A and Harikumar K R 1998 Chem. Phys. Lett. 287671

20. Stéphan O, Ajayan P M, Colliex C and Redlich Ph 1994 Science 2661683

21. Ma R and Bando Y 2002 Chem. Mater. 144403

22. Wu J, Han W Q, Walukiewicz W, Ager J W III, Shan W, Haller E E and Zettl A 2004 Nano Lett. 4647

23. Xu X, Yang L J and Jiang S J 2011 Chem. Commun. 47 7137

24. Dong J P, Qu X M and Wang L J 2008 Electroanalysis 181981

25. Pokropivny V V, Shorokod V V and Oleinik G S 2000 J. Solid State Chem. 154214

26. Gao R, Yin L W and Wang C X 2009 J. Phys. Chem. C 11315160

27. Caretti I, Jim J and Albella J M 2003 Diam. Relat. Mater. 121079

28. Kim D H, Byon E and Lee S 2004 Thin Solid Films 447448192

29. Zhou Z F, Bello I and Lei M K 2000 Surf. Coatings Technol. 128-129 334

30. Yap Y K, Kida S and Aoyama T 1998 Appl. Phys. Lett. 73915

31. Yap Y K, Kida S, Wada Y, Yoshimura M and Mori Y 2000 Diam. Relat. Mater. 91228 
32. Kan K, Xia T L, Li L and Bi H M 2009 Nanotechnology 20185502

33. Berns D H and Cappelli A 1996 Appl. Phys. Lett. 682711

34. Zhang T, Wen G W and Huang X X 2010 Cryst. Eng. Commun. 123506

35. Chen Y, Zou J and Campbell S J 2004 Appl. Phys. Lett. 842430

36. Linss V, Rodilb S, Reinkec P and Garnierd M 2004 Thin Solid Films 46776.
37. Mannan M A, Nagano M and Kida T 2009 J. Phys. Chem. Solids 7020

38. Tamikuni K 2004 J. Mater. Chem. 14221

39. Zhang R, Li L and Chen L 2011 J. Alloys Compd. 509 8620

40. Lv W X, Zhang R, Xia T L, Bi H M and Shi K Y 2011 J. Nanopart. Res. 132351

41. Maldonado S, Morin S and Stevenson K J 2006 Carbon 441429 